\section{POLÍTICA, SOCIEDAD Y ÉTICA A TRAVÉS DE LA HERMENÉUTICA ANALÓGICA}

\author{
Mauricio Beuchot \\ Instituto de Investigaciones Filológicas \\ Universidad Nacional Autónoma de México \\ mbeuchot50@gmail.com
}

\section{POLITICS, SOCIETY AND ETHICS THROUGH ANALOGUE HERMENEUTICS}

Cómo citar este artículo/ Citation: Beuchot, M. (2013). "Política, sociedad y ética a través de la hermenéutica analógica". Arbor, 189 (761): a040. doi: http://dx.doi.org/10.3989/ arbor.2013.761n3008

Recibido: 15 abril 2011. Aceptado: 25 octubre 2012.

RESUMEN: En este artículo intento aplicar la hermenéutica analógica al tema de la política, principalmente a través de la filosofía política. Así como antes se desconectó la política de la ética, ahora se procura volverlas a conectar. Se trata de tener un estado legítimo, no solamente legal. Y la razón es que debe garantizar los derechos humanos para la sociedad civil, la cual ejerce, dentro de ellos, su solidaridad.

PALABRAS CLAVE: Hermenéutica analógica, política, ética, derechos humanos, sociedad civil.
Copyright: (c) 2013 CSIC. Este es un artículo de acceso abierto distribuido bajo los términos de la licencia Creative Commons Attribution-Non Commercial (by-nc) Spain 3.0.

ABSTRACT: In this article I set out to apply Analogic Hermeneutics to the subject of Politics, mainly through the Philosophy of Politics. Thus, as Ethics has been disconnected from Politics in the past, the effort here is to reconnect them. We need to have a state that is legitimate rather than merely legal, because it ought to guarantee Human Rights for civil society, which exercises solidarity within the limits human rights define.

KEYWORDS: Analogical hermeneutics, politics, ethics, human rights, civil society. 


\section{INTRODUCCIÓN}

La filosofía política es el estudio de las formas de sociedad a la luz de la ética, buscando el modo en que realizan la justicia y logran el bien común. Por supuesto que hay una forma meramente descriptiva de hacer filosofía política, en la que solo se registra lo que ocurre en el panorama político mundial; pero también es posible una filosofía política crítica, que juzga, precisamente, a partir de una noción de sociedad ideal, en la cual plasma los valores éticos conforme a la idea de hombre que le subyace.

Por lo cual, dicha filosofía política actúa desde una interpretación del ser humano (tanto antropológicofilosófica como, sobre todo, ética), y esto hace que haya de fondo una hermenéutica que construye la filosofía política, y aquí deseamos que sea una hermenéutica analógica, que evite los excesos de una hermenéutica unívoca, la cual daría una idea de sociedad impositiva y totalitaria y los de una hermenéutica equívoca, que daría una idea de sociedad demasiado fragmentada, atomizada en un relativismo que conduciría a la larga a la disolución social. Por eso hemos de ser muy cuidadosos con la hermenéutica que elegimos para construir nuestra filosofía política, nuestra visión de la sociedad (Beuchot, 2006).

\section{HERMENÉUTICA TRANSFORMADORA, UTÓPICA Y PROFÉTICA}

En algún momento, se consideró que la hermenéutica era políticamente neutral. Lo sostuvo Habermas en relación con Gadamer y Ricoeur. Con ello acusaba a la hermenéutica de apolítica y conservadora. Gadamer respondió que la hermenéutica no tenía una función directamente crítica, y lo mismo Ricoeur, diciendo que no hacía crítica de las ideologías (Ricoeur, 1982). Sin embargo, después, tanto uno como otro aceptarán que la hermenéutica tiene implicaciones políticas; Gadamer, por el reconocimiento de aspectos o ingredientes éticos que lleva implícita la hermenéutica, y Ricoeur, en su libro Ideología y utopía, al reconocer que la hermenéutica tiene que distinguir entre lo utópico que es meramente ideológico y lo utópico que es orientador hacia el bien (Ricoeur, 2001).

Más aún, recientemente se ha hablado de la capacidad crítica (política) que puede tener la hermenéutica. Si está dedicada a la comprensión, puede dar el paso hacia el juicio, hacia la crítica (krínein en griego significa igualmente juzgar que criticar). Más aún, en esa línea va la hermenéutica crítica de Adela Cortina y Jesús Conill, que retoma ideas de Apel y Habermas, al igual que de la hermenéutica de Gadamer y Ricoeur. E incluso se puede hacer una incorporación de la hermenéutica analógica en la hermenéutica crítica, a modo de hermenéutica analógico-crítica de la sociedad y sus instituciones (Arenas-Dolz, 2003).

Resuena en nuestros oídos la tesis 11 de Marx sobre Feuerbach, en la que asienta que los filósofos se han dedicado a interpretar el mundo, y que lo que hace falta es cambiarlo (Marx, 1963). ¿Será posible una hermenéutica que transforme el mundo además de interpretarlo? ¿Está la hermenéutica condenada a solo interpretar el mundo sin poder nunca transformarlo? Creo que la hermenéutica puede ayudar a cambiar, sobre todo desde su función de interpretar. En efecto, no se trata de comprender por comprender, hay que comprender para transformar. $Y$ la hermenéutica comienza a tener un papel muy importante en ello, pues ¿cómo se va a transformar si primero no se interpreta?

Inclusive se ha hablado de un "giro hermenéutico en la filosofía política" (Warnke, 1993). Aquí es donde vemos que no se aplica la falacia naturalista (la cual se tipifica como el paso del ser al deber, del hecho al valor, de la descripción a la valoración o prescripción), porque tenemos que interpretar al hombre para poder pensar en la sociedad que le resulta adecuada o conveniente. Hay que ver el contexto en el que habita, para ver si esa sociedad o una distinta es la que le viene bien. Pues también podemos criticar la sociedad actual y pensar en una distinta, así sea utópicamente.

Por eso la hermenéutica puede tener un ángulo utópico, es decir, atreverse a proponer, después de la crítica a la sociedad real, una sociedad ideal, en la que el ser humano encuentre las condiciones de posibilidad de su realización plena como ente social. Y, en ese sentido, es una hermenéutica no solo utópica, porque propone mejoras ideales (Ricoeur, 2001), sino, además, una hermenéutica profética, es decir, que, después de atender a la esencia del hombre, habla en su nombre. Sobre todo, es profética porque habla de la ética en la política, y de la ética de acuerdo a lo que se considera que es la naturaleza humana.

De esta manera, la hermenéutica puede tener un papel relevante en la filosofía política, porque interpreta al hombre y con ello puede ver qué tipo de sociedad le conviene; y porque interpreta a la sociedad misma, con lo cual puede comprenderla y criticarla, e incluso proponer cambios o una sociedad nueva, con lo cual puede ser transformadora, utópica y profética. La hermenéutica es, así, un recurso metodológi- 
co para la filosofía política. Además, la hermenéutica puede asumirse como hermenéutica analógica, es decir, que trata de evitar los extremos de la hermenéutica univocista, la cual impone un totalitarismo, y los de la hermenéutica equivocista, que abandona a una atomización relativista de la sociedad en la que acaba por reinar el caos. Una hermenéutica analógica buscará el bien común, la equidad y la justicia; más aún, tiene el esquema de la justicia, sobre todo el de la justicia distributiva, que es desde antiguo y más todavía recientemente el que se ve como más necesario para la política y la sociedad.

\section{ESTADO DE DERECHO Y DERECHOS HUMANOS}

Lo primero que nos muestra una filosofía política vertebrada con la hermenéutica analógica es que la sociedad está formada por un estado y una sociedad civil, proporcionalmente legítimos. Es decir, que el estado, que es el que gobierna, tiene que estar avalado por su legitimidad, no solamente por su legalidad; es decir, no solo que sea conforme a las leyes, sino a las leyes justas ( $y$, en ese sentido, legítimo por su origen y por su desempeño); y esto involucra la ética en la política (Höffe, 2003). De alguna manera la modernidad trató de separar la ética de la política, por ejemplo con Maquiavelo, dejando al estado, en este caso al gobernante, por encima de la ley, y con poder más allá de lo moral. La simple presencia de la ley o el derecho da la legalidad, pero el estar de acuerdo con la ética da la legitimidad, como lo ha señalado Habermas.

Sobre todo, es una sociedad y un estado asentado en los derechos humanos, que se plasman en su constitución como derechos fundamentales, lo que antes se llamaba las garantías individuales. Eso es lo mínimo con lo que se puede contar, a saber, con un estado justo, que realiza la justicia dando a todos los ciudadanos la igualdad ante la ley, la igualdad de oportunidades y la igualdad de atribuciones. Pero esto no basta. También se tiene que garantizar la libertad de elegir ideales de vida buena, de realización, plenitud o felicidad. Y esto rebasa lo mínimo. Por eso Adela Cortina los ha llamado mínimos de justicia y máximos de buena vida. Mínimos, porque es lo menos que se puede pedir, y es fácil concitar el consenso acerca de ellos (Cortina, 1995). Máximos, porque son cosas que van más allá de la justicia y pertenecen al bien, y es difícil lograr el consenso acerca de ellos. Pero tienen que integrarse, ya que son, precisamente, esos máximos de vida buena los que dan sentido a los mínimos de justicia, son los que los hacen apetecibles, se buscan en función de ellos o para ellos.
Es también lo que resulta del contrato social o pacto político, y del consenso traslapado del que habla Rawls (Grueso, 1997). Es la igualdad que se da en el velo del desconocimiento frente a las diferencias de oportunidades. Es lo que propicia el equilibrio reflexivo, parecido al juicio reflexionante de Kant y a la phrónesis aristotélica. Es el ejercicio de la analogicidad, señalado por Hannah Arendt como el sensus communis kantiano, consistente en "ponerse en el pellejo del otro", o de los demás, para entender sus necesidades y deseos legítimos (Sánchez, 2003). De eso surgirá la solidaridad, virtud eminentemente política, que va más allá de la tolerancia, incluso más allá del respeto, e implica aceptación, se coloca como reconocimiento, del que tanto habla Charles Taylor. Esa política del reconocimiento requiere que tengamos una actitud abierta, sobre todo frente a lo diverso, lo diferente.

Antiguamente se decía que la sociedad se realizaba en vistas al bien común. Ése era su objetivo. Se realizaba por el logro de la justicia, la cual aseguraba la paz, e incluso el bienestar social. Pero se ha visto que no basta un estado de bienestar. Tiene que haber sentido, por eso el estado debe proporcionar lo que posee un papel de donación de sentido en las sociedades, lo que ejerce una función simbólica. Es decir, el gobernante tiene que saber de la cultura, de las culturas que conviven en un estado, en una sociedad. Por eso, también, la sociedad debe proporcionar un sano interculturalismo. Ir más allá del mero multiculturalismo, que solamente permite convivir sin destrozarse, para prever que las culturas interactúen, y que lo hagan bien, enriqueciéndose.

Una muestra del estado de derecho son los derechos humanos, que se plasman en la constitución de dicho estado como derechos fundamentales, lo que antes se llamaba garantías individuales. Algunos los han visto como derechos naturales, otros como puramente positivos, y otros como derechos morales (moral rights). Esta consideración de los derechos humanos como derechos morales, intermedia entre la iusnaturalista y la iuspositivista, nos hace ver que se puede llegar a una base o fundamento iusnaturalista de los derechos humanos que no relegue la positivación de los mismos, pero que no haga depender todo su valor de la mera positivación. De hecho, ya el iusnaturalismo no es tan exigente como antes, ni el iuspositivismo es tan rígido. Han llegado a una integración, por ejemplo en autores como Dworkin y Atienza. Ninguno de ellos se llamaría iuspositivista, ambos admiten una validez de los derechos humanos más allá de la sola positivación, pero tampoco llegarán a 
un iusnaturalismo tan extremo como, por ejemplo, el de la llustración (ya que el antiguo era más dinámico y menos rígido, por ejemplo el aristotélico).

Y es que un estado de derecho, es decir, uno asentado sobre la base de los derechos humanos, es el que puede permitir la democracia. De otra manera nos caerá la imposición univocista de los totalitarismos, o la desestructuración equivocista de los regímenes sin sostén ni límites. Se requiere un estado analógico para que haya democracia, una democracia basada en los derechos humanos, de modo que haya respeto para el estado y para la sociedad civil, para los ciudadanos. Allí todos los ciudadanos tienen igualdad ante la ley, igualdad de oportunidades, e igualdad en la participación política.

\section{LAS VIRTUDES POLÍTICAS}

Ya que el objetivo de la sociedad política es el bien común, según decía Aristóteles, los hombres se reúnen para satisfacer mejor sus necesidades, tanto materiales como espirituales, y, además, para el amor o la amistad (Aristóteles, 1961). Pero esto requiere que se cumpla la justicia en la sociedad. Por eso para la vida en comunidad son necesarias ciertas virtudes, que ya el propio Estagirita señalaba.

En este sentido, se necesita la prudencia o phrónesis, ya que es la virtud que da la sensibilidad para el término medio de las acciones, que es el que da el modus o medida de la convivencia. Para eso hay una prudencia personal, una doméstica y una política. En el caso de la prudencia política, hay una prudencia del gobernante y otra del gobernado. El gobernante es prudente en su relación con los súbditos o gobernados no imponiendo demasiadas cargas, mandando con moderación, etc.; y el gobernado ejerce la prudencia no siendo insolente con el gobernante, y teniendo disposición para colaborar en la construcción del bien común, no solo del individual.

La templanza es aquí, según la interpretación política que le da Bobbio, como la actitud de no querer acaparar todo, de dejar algo para los demás; no tanto contenerse en la satisfacción de las necesidades y los deseos, sino el dejar para los otros elementos que puedan aprovechar oportunidades, bienes, servicios, etc. (Bobbio, 1997). La fortaleza es la decisión de mantenerse firme y constante en esa templanza, y permanecer en ese camino de la virtud.

Pero sobre todo se requiere la justicia, que es la voluntad estable de dar a cada quien lo suyo, lo que se le debe, lo cual es sumamente analógico, ya que es darle a cada quien la porción que le toca, esto es, su proporción, la proporción analógica que le es debida. Hay una justicia conmutativa, otra distributiva y otra legal. La conmutativa es la que se da en la relación de los particulares entre sí, como en los tratos y contratos, las compraventas, etc. La distributiva es la que se da entre el estado y los ciudadanos, en la distribución de los bienes comunes, cargos y cargas, pero también de oportunidades y servicios. La legal es de los individuos hacia el estado, al cumplir las leyes; pero también del estado hacia los individuos, al administrar bien el derecho y respetar los derechos de cada uno.

Así, la justicia es la corona o culmen de la vida social. Justicia entre los individuos y los grupos; en las relaciones del estado con los ciudadanos y de los ciudadanos con el estado. Es lo que posibilita la paz y la felicidad. Solo si hay el mínimo de justicia podrá haber el máximo de felicidad o buena vida (Williams, 1993).

También es una virtud ser utópico. Es una magnanimidad del teórico, del filósofo. No se nos agota nuestro filosofar en la praxis, en un realismo obtuso; llegamos hasta la teoría, y aun en ella nos ponemos como en una atalaya. En toda filosofía política hay un poco de utopía, tiene un trasfondo de esperanza. Es verdad que tiene una parte más descriptiva, en la que reflexiona sobre lo que está ocurriendo, pues no nos podemos dar el lujo de cerrar los ojos ante la realidad, de ser demasiado idealistas. Pero también es verdad que tiene una parte más propositiva, más futurista, que es donde se ubica la dimensión utópica. Siempre, al hacer filosofía política, pensamos en una sociedad ideal, una ciudad o polis utópica.

Más aún, la utopía cobra mayor presencia al considerar que ha sido fuente de sentido, y ahora estamos en un tiempo demasiado vacío de sentido. Hay una gran bonanza económica, con la globalización, pero deja de lado a muchos; y, aun a los que incluye, incorpora e integra, no parece darles suficiente sentido. Es una sociedad consumista, hedonista y ególatra; ésos parecen ser los valores actuales. Pero tal parece que no dan felicidad (Magallón, 2009).

Por eso, aunque es imprescindible lograr la igualdad ante el derecho o la ley y ante la distribución, eso no es suficiente; es decir, la justicia no basta; hay que añadir las ideas de plenitud, realización y vida buena, o felicidad, que son las que dan sentido a lo otro. Hay mínimos de justicia y máximos de vida buena, pero son precisamente los máximos de felicidad los que dan sentido a los mínimos de justicia. Estos mínimos de justicia son como la referencia de la sociedad, y los 
máximos de felicidad son como el sentido que tiene o puede ofrecer.

Y es que la ilusión que tenemos, al hacer filosofía política, es que esta se lleve a la práctica, que llegue a la praxis, que pase de la teoría a la acción, de lo abstracto a lo concreto, que nuestro teorizar llegue a servir a los seres humanos individuales, existentes, reales, vivos. En este sentido, la filosofía política tiene un aspecto hermenéutico, y se abre a una hermenéutica analógica, pues se trata de interpretar al ser humano, a la sociedad, para abrirle caminos políticos.

\section{GLOBALIZACIÓN E INCLUSIÓN}

Esta filosofía política crítica tiene como principal trabajo enjuiciar la globalización que nos inunda, la cual es el fenómeno social, político y económico más importante que tenemos en la actualidad. Como lo han hecho ver muchos estudiosos, entre ellos Enrique Dussel, desde su punto de vista de la analéctica, que usa de la analogía para plantear una postura transmoderna, lo que más hace falta es que la globalización sea incluyente, ya que hasta ahora no lo ha sido (Dussel, 1996). Deja de lado a los desposeídos, deja a su paso muchos pobres, excluidos de los beneficios que reporta a unos pocos, comparativamente hablando (Dussel, 1998).

Al ser crítica, esa filosofía política está reconectándose con la ética, que es lo que pedíamos para que fuera utópica y profética. Y esto lo puede hacer desde la analogía, esto es, desde la analéctica y la hermenéutica analógica, ya que la analogía nos hace ver la proporción y la desproporción. Aquí se cumple lo que pedía Iván Illich, el pensador de Cuernavaca, quien hablaba de recuperar la proporción para la política, para la sociedad. Y la proporción es la analogía ("analogía" significa en griego "proporción"). Una sociedad proporcional o proporcionada al hombre, para que él encuentre sentido en ella, una sociedad al tamaño del hombre, para que sea habitable para él, esto es, para que sea humana.

Lo transmoderno, planteado por Dussel, no es lo posmoderno, aunque comparte con ello la crítica de la modernidad; pero lo posmoderno ha hecho críticas parciales a la modernidad, y ha dejado pasar de ella, o ha aceptado, errores o males que ella tenía, como la injusticia, la exclusión (Dussel, 2001). Habermas ha dicho que esto se da porque la modernidad no ha podido cumplir sus ideales de justicia, ya que ha quedado como un proyecto inacabado, incompleto, inconcluso; pero lo cierto es que la modernidad no cumplió esa promesa, como tampoco se halla en la posmodernidad, por lo que alguien tiene que recuperarla, plantearla y cumplirla, y ésa puede ser la transmodernidad.

Esta ética de la no exclusión es un esfuerzo por dialectizar la analogía, por eso Dussel la llama analéctica y a veces anadialéctica (Dussel, 1991). La dialéctica es la que vigoriza e impulsa la analogía, y por eso puede dinamizar a la hermenéutica analógica, para que no se quede impasible ante los excluidos, los desposeídos. Tiene que preocuparse por señalar caminos, pautas de acción que resulten de la interpretación de la realidad y de la proyección hacia el futuro, así se superará la mera hermenéutica unívoca de la sociedad real y la sola hermenéutica equívoca de los proyectos descabezados, de las utopías irrealizables; esa hermenéutica analógica conduce a lo que Dussel Ilama, desde la analéctica, una utopía realizable.

\section{LA LUCHA DE LOS SISTEMAS: MÁS ALLÁ DEL LIBERA- LISMO Y DEL COMUNITARISMO}

La hermenéutica analógica muestra un camino en el que se puede buscar una relación más mesurada y equilibrada entre el liberalismo y el comunitarismo, que son los antagonistas actuales, y que a veces parecen llegar a un impasse (Mulhall, Swift, 1993). Son tantas las críticas que han recibido los unos de los otros, que se ha llegado a posturas intermedias, proporcionales, esto es, analógicas, en las que ya no se da esa polarización tan grande. Por ejemplo, el liberal Rawls ha tomado en cuenta muchas críticas que le han hecho los comunitaristas, y llega a un liberalismo moderado. El comunitarista Taylor ha reflexionado tanto sobre las objeciones que se le han opuesto, que llega a ser un comunitarista moderado (Taylor, 1997).

Por eso conviene evitar el univocismo del liberalismo, que únicamente ve por la libertad, de modo individualista y hasta egoísta, y también evitar el equivocismo de un comunitarismo relativista (pues el relativismo se da, más que de los individuos, de las comunidades). Hay que ir, de manera analógica, a un liberalismo social, que es la postura que adoptó Rawls al final, por obra de las críticas de los comunitaristas a su liberalismo inicial; o a un comunitarismo patriótico, al que llegó Taylor, que es un comunitarismo no relativista, sino que busca lo que de común se puede alcanzar entre los actores involucrados en la sociedad (individuos y comunidades). Se busca un equilibrio entre la aplicación seca de la ley, como en el liberalismo procedimental, y la aplicación tan diferenciada que se diluya, en un comunitarismo que se disuelve 
en las aspiraciones de las comunidades, que introducen diversas interpretaciones de las mismas leyes o de los derechos, incluso de los derechos humanos (Blanco, 2000). Por ejemplo, se trata de dar a los derechos humanos, que son individualistas, por su origen liberal, un sentido más comunitario y solidario.

Inclusive hay un repunte del republicanismo, que deja lugar a las diferencias. Cada vez se busca más la manera de integrar las diferencias, pero sin perder la capacidad de incorporar lo universal. Han sido muy importantes las posturas de género, de minorías y otras, para llamar la atención hacia el reconocimiento de los demás.

Por eso también ha sido importante el problema del multiculturalismo. Es también un tema de filosofía política. Kymlicka presenta un modelo de pluralismo cultural más cercano al univocismo, porque pide que se deje convivir a las culturas, pero falta la interacción entre ellas. Así, Sartori pide que a cada cultura se le deje hacer lo que ha hecho, en un equivocismo que nos impedirá criticar y frenar, por ejemplo ante la lesión de los derechos humanos. Me parece más adecuado Taylor, más analógico, que nos mueve a permitir las diferencias lo más posible, pero sin perder la capacidad de integrarlas en alguna universalidad (Lazo, 2007).

Tienen como muy importantes las representaciones colectivas, los imaginarios sociales, que luego nos condicionan. Y hay que crear la posibilidad de dialogar desde ellos. La parte de las culturas más problemática no es tanto la de la economía y la política, sino la de lo simbólico (religión, costumbres, instituciones, etc.). Es la convivencia de instituciones distintas, a veces contrarias. $Y$ todo eso dentro de la globalización actual, que cuestiona a todas las filosofías políticas.

\section{CONCLUSIÓN}

La filosofía política recupera su misión de encaminar a la sociedad a la consecución del bien común. Ese bien común se alcanza en la justicia, que es equidad, esto es, igualdad proporcional ante la ley, ante las oportunidades y ante la participación política. Esto nos da una filosofía política crítica, ya que muchas veces nos encontramos con que no se tiene, y ni siquiera se busca, este ideal de justicia. Por ejemplo, en la actual globalización económica se ve que no es incluyente, sino excluyente, deja a muchos pobres fuera de los beneficios que conlleva, por el hecho de que no pueden participar en esa compra-venta que implica, no tiene competitividad, ni siquiera poder adquisitivo.

Esta filosofía política crítica puede vertebrarse con una hermenéutica, con tal de que sea una hermenéutica crítica. Y también puede ayudarse de la analogía, como lo hemos visto en la analéctica de Dussel, que intencionadamente quiere ser una filosofía política crítica, y la hermenéutica analógico-crítica, que es la fusión de la hermenéutica crítica de Adela Cortina y Jesús Conill con la hermenéutica analógica, por obra del Prof. Francisco Arenas-Dolz (Arenas-Dolz, 2004). Es un camino que se está recorriendo, y que promete llevar a un estado mejor de la sociedad.

\section{BIBLIOGRAFÍA}

Arenas-Dolz, F. (2003). Hacia una hermenéutica analógico-crítica. México: Número especial de Analogía, 12.

Arenas-Dolz, F. (2004). "Retorética. Actualidad de la hermenéutica analógico-crítica". En I. Murillo (Ed.), Filosofía práctica y persona humana (pp. 625-634). Salamanca: Eds. Diálogo Filosófico.

Aristóteles (1961). Política, I, 1. Ed. I. Bekker. Berlin: Walter de Gruyter.

Beuchot, M. (2006). Filosofía política. México: Ed. Torres.

Blanco Fernández, D. (2000). Principios de filosofía política. Madrid: Síntesis.
Bobbio, N. (1997). Elogio de la templanza $y$ otros escritos morales. Madrid: Eds. Temas de hoy.

Cortina, A. (1995). Ética civil y religión. Madrid: PPC.

Dussel, E. (1991). Método para una filosofía de la liberación. Superación analéctica de la dialéctica hegeliana. Guadalajara (México): Universidad de Guadalajara.

Dussel, E. (1996). “La analogía de la palabra (el método analéctico y la filosofía latinoamericana)". Analogía filosófica, vol. 10 , no. 1 , pp. 29-60.
Dussel, E. (1998). Ética de la liberación en la edad de la globalización y la exclusión. Madrid: Trotta.

Dussel, E. (2001). Hacia una filosofía política crítica. Bilbao: Desclée de Brouwer.

Grueso, D. I. (1997). Rawls, una hermenéutica pragmática. Cali (Colombia): Universidad del Valle.

Höffe, O. (2003). Justicia política. Barcelona: Paidós.

Lazo Briones, P. (2007). Interpretación y acción. El sentido hermenéutico del pensamiento ético-político de Charles Taylor. México: Eds. Coyoacán. 
Magallón Anaya, M. (2009). "Ética y pensamiento crítico latinoamericano en el siglo XXI". En L. G. Díaz Núñez (ed.), Ética y globalización. Una mirada interdisciplinaria (pp. 55-94). México: Ed. Torres.

Marx, K. (1963). "Thèses sur Feuerbach". En N. Guterman y H. Lefevbre (eds.), Oeuvres choisies. Paris: Gallimard.

Mulhall, S. y Swift, A. (1993). Liberals and Communitarians. London: Blackwell.
Ricoeur, P. (1982). "Hermeneutics and the Critique of Ideology". En Paul Ricoeur, Hermeneutics and the Human Sciences. Cambridge: Cambridge University Press - Paris: Éditions de la Maison de sciences de l'homme.

Ricoeur, P. (2001). Ideología y utopía. Barcelona: Gedisa.

Sánchez Muñoz, C. (2003). Hannah Arendt. El espacio de la política. Madrid: Centro de Estudios Políticos y Constitucionales.
Taylor, Ch. (1997). "Equívocos: el debate liberalismo-comunitarismo". En Argumentos filosóficos. Ensayos sobre el conocimiento, el lenguaje y la modernidad. Barcelona: Paidós.

Warnke, G. (1993). Justice and Interpretation. Cambridge, Mass.: The MIT Press.

Williams, B. (1993). "La justicia como virtud". En La fortuna moral. México: Universidad Nacional Autónoma de México. 